\title{
Construção de uma tarefa de reconhecimento de tradução Libras-Português: considerações metodológicas
}

\author{
Construction of a translation recognition task in Libras-Portuguese: methodological considerations
}

\author{
Sandro Rodrigues da Fonseca \\ Ana Beatriz Arêas da Luz Fontes \\ Ingrid Finger \\ Universidade Federal do Rio Grande do Sul, Porto Alegre, RS, Brasil
}

\begin{abstract}
Resumo: Este artigo tem como objetivo refletir sobre aspectos metodológicos importantes a serem adotados na elaboração de uma tarefa psicolinguística que investiga o acesso lexical no bilinguismo bimodal. A Tarefa de Reconhecimento de Tradução Libras e Português apresentada aqui foi construída no decorrer da pesquisa que deu origem à dissertação de mestrado de Fonseca (2015), que investigou o efeito de interferência semântica em bilíngues bimodais ouvintes que atuam como TILS - tradutores e intérpretes de Libras, com distintos níveis de experiência profissional. Este artigo observa em que medida a tarefa atingiu sucesso e discute a necessidade de criar tarefas confiáveis em estudos psicolinguísticos envolvendo línguas de sinais.

Palavras-chave: Tarefa de reconhecimento de tradução; Libras; Bilinguismo bimodal; Psicolinguística; Acesso lexical

Abstract: The goal of the present article is to reflect on important methodological aspects to be adopted during the construction of a psycholinguistic task that investigates lexical access in bimodal bilingualism. The Translation Recognition Task presented here was created during the research that gave origin to the master's dissertation of Fonseca (2015), which investigated the semantic interference effect in hearing bimodal bilinguals who work as TILS - sign language translators and interpreters, with distinct levels of professional experience. The present article observes the extent to which the task was successful and discusses the need of developing reliable tasks in psycholinguistic studies involving sign languages.
\end{abstract}

Keywords: Translation recognition task; Libras; Brazilian Portuguese; Bimodal bilingualism; Psycholinguistics; Lexical access; Semantic interference

\section{Introdução}

A investigação psicolinguística sobre o processamento da Libras - Língua Brasileira de Sinais representa uma oportunidade importante para a ampliação da compreensão do bilinguismo que se apresenta na modalidade visuoespacial e pode fornecer respostas a vários questionamentos científicos relacionados à natureza da Libras e sua relação com as línguas orais, mais precisamente, com o Português Brasileiro. Nesse sentido, tarefas experimentais, como a apresentada neste artigo, podem se tornar instrumentos valiosos para a compreensão e produção de modelos psicolinguísticos capazes de fornecer maior discernimento sobre como as diferentes línguas dos bilíngues se estruturam e sobre como o processamento linguístico ocorre nesses casos.

Nesse contexto, o presente artigo tem como objetivo descrever a construção de uma Tarefa de Reconhecimento de Tradução, especialmente elaborada como parte de um estudo psicolinguístico que investigou a organização e processamento bilíngue bimodal no par Libras e Português Brasileiro em um grupo de bilíngues bimodais ouvintes que atuam como TILS - tradutores e intérpretes de Libras, com distintos níveis de experiência profissional. Assim, serão consideradas as especificidades dos estudos envolvendo tarefas experimentais dessa natureza, bem como serão discutidos os critérios e etapas levados em conta na elaboração e aplicação da tarefa, que foi 
desenhada considerando características do bilinguismo bimodal Libras - Português. Com isso, espera-se contribuir com a Psicolinguística do Bilinguismo, salientando a necessidade de se empregar rigor metodológico na construção de instrumentos psicolinguísticos para estudos com bilíngues bimodais que focam na compreensão dos aspectos relativos à organização e ao processamento linguístico da Libras.

\section{O processo de criação da Tarefa de Reconhecimento de Tradução}

O uso de uma Tarefa de Reconhecimento de Tradução tem como principal vantagem a possibilidade de comparar a reação dos participantes do estudo quando há alguma relação lexical ou semântica entre duas palavras de línguas diferentes (CHRISTENSEN; JOHNSON; TURNER, 2014; JIANG, 2012; SHADISH; COOK; CAMPBELL, 2001). A tarefa consiste basicamente em solicitar ao participante que observe duas palavras diferentes (prime e alvo), apresentadas uma após a outra na tela do computador, e diga se a segunda palavra corresponde à tradução da primeira. O participante responde afirmativamente ou negativamente, apertando as teclas do teclado marcadas por um $\mathrm{S}$ e um $\mathrm{N}$, respectivamente. A tarefa procede com o participante respondendo a uma sequência de estímulos dessa maneira até o final da tarefa. O programa utilizado para a elaboração da tarefa (E-Prime 2.0) registra as respostas dos participantes e o tempo de reação (ou seja, o tempo que o participante leva para reagir ao estímulo respondendo se o item alvo é, em sua opinião, uma tradução do prime) e os salva para futura análise.

É importante lembrar que para a composição eficaz de uma Tarefa de Reconhecimento de Tradução é necessário ter atenção às diferentes variáveis que podem afetar o estudo. Essas podem estar relacionadas às características do léxico utilizado na Tarefa de Reconhecimento de Tradução como, por exemplo, a classe gramatical e o nível de abstração das palavras utilizadas como estímulo. Essa preocupação existe, especialmente, em estudos que investigam relações de causa e efeito entre diferentes variáveis. Para que se possa estabelecer essa relação é necessário deixar claro o que se entende por variáveis independentes, dependentes e de confusão. As diferenças entre esses tipos de variáveis serão discutidas abaixo.

A variável independente, em uma Tarefa de Reconhecimento de Tradução, pode ser, por exemplo, a concretude do prime. Por exemplo, o par amor-love possui um prime abstrato, enquanto o par casa-house possui um prime concreto. Nesse caso, a tarefa estaria testando o efeito da concretude na tradução, ou seja, se há diferenças no reconhecimento de tradução de palavras concretas e abstratas. As variáveis dependentes são as medidas de tipo de resposta (percentual de erros) e do tempo (tempo de reação) que o participante leva para reconhecer o alvo como a tradução do prime dependendo da concretude do prime. Finalmente, em um estudo dessa natureza, é importante também controlar as variáveis que podem originar efeitos de confusão nos resultados, através da adoção de alguns procedimentos metodológicos que serão apresentados na próxima seção.

\section{O controle de variáveis no bilinguismo bimodal}

Dentro do contexto bilíngue bimodal é necessário lidar com diferentes variáveis de ordem linguística e extralinguística que podem afetar os resultados obtidos a partir de uma tarefa psicolinguística, levando em consideração aspectos da modalidade visuoespacial da Libras e características específicas de seu uso. Nesse sentido, estudos que utilizam a Tarefa de Reconhecimento de Tradução se beneficiam do conhecimento das características lexicais da palavra ou do sinal. A Libras, assim como outras línguas de sinais, apresenta uma organização em vários níveis linguísticos (FERREIRA, 2010a; QUADROS; KARNOPP, 2004a; SANDLER; LILLO-MARTIN, 2006). Por exemplo, os sinais se organizam do ponto de vista fonológico, por meio dos parâmetros configuração de mão, locação, movimento, e de aspectos ainda sob debate como a orientação da palma da mão e o caminho ou trajetória percorrido durante o movimento, além de aspectos não manuais. A configuração de mão diz respeito à forma como a mão é posicionada no momento em que o sinal é articulado. A realização do sinal ainda depende de sua locação, ou seja, da posição em que o sinal é articulado em relação ao corpo da pessoa, e da trajetória do movimento realizado. Expressões não manuais, como as expressões faciais e o movimento dos ombros e do tronco durante a sinalização, são também considerados gramaticais no uso da Libras

Todos esses aspectos linguísticos e extralinguísticos precisam ser observados no momento da escolha dos sinais que comporão uma tarefa psicolinguística. Para que seja possível construir uma tarefa para um estudo de causa e efeito, é necessário isolar a variável de estudo e excluir, randomizar ou então equiparar as demais características para que se tenha mais segurança de que a variável independente é a que está causando o efeito durante o estudo. A seguir, exemplificamos o papel de três variáveis importantes em estudos sobre o léxico das línguas de sinais, que são a frequência de ocorrência, a iconicidade e a co-ativação das línguas. 


\section{Frequência de ocorrência, iconicidade e co-ativação bilíngue}

A quantidade de vezes que uma palavra é utilizada em uma língua é um fator importante a ser considerado. Ela é capaz de produzir o que se constitui um efeito importante para os estudos psicolinguísticos: o chamado efeito de frequência de ocorrência de palavras. Dentre os trabalhos que descrevem esse efeito, destaca-se a pesquisa de De Groot (1992), que demonstrou em que medida a frequência de ocorrência das palavras nas línguas atua como um dos fatores determinantes para a sua tradução. No primeiro estudo, 48 estudantes do primeiro ano de psicologia na Holanda, bilíngues não balanceados, que possuíam o holandês como primeira língua e inglês como segunda língua, realizaram uma tarefa na qual foram solicitados a ler uma palavra em holandês na tela do computador para, em seguida, verbalizar a sua tradução. Essa tarefa foi executada em duas condições: tradução normal e tradução com uma dica, sendo que na primeira condição o computador exibia unicamente a palavra que deveria ser traduzida, ao passo que na segunda condição os participantes viam a palavra a ser traduzida em holandês juntamente com a primeira letra da palavra da sua tradução em inglês. $\mathrm{O}$ tempo de reação foi registrado a partir do momento que os participantes começavam a dar a sua resposta e o pesquisador anotava as respostas para verificação de acertos. No segundo experimento, os participantes realizaram uma Tarefa de Reconhecimento de Tradução, semelhante à tarefa reportada neste artigo, na qual foram solicitados a ler, em uma tela de computador, pares de palavras em inglês e holandês e respondiam se elas eram ou não equivalentes de tradução, pressionando a tecla apropriada no computador. Dentre as variáveis selecionadas para o estudo, a frequência de ocorrência das palavras foi manipulada de forma que a tarefa continha palavras com alta e baixa frequência de ocorrência. Os resultados obtidos indicaram que houve uma facilitação na tradução nas condições de alta frequência de ocorrência, colocando esta variável como um dos fatores determinantes no processo de tradução.

Nas línguas de sinais, Emmorey (1990) foi pioneira na verificação do efeito da frequência de ocorrência na Língua de Sinais Americana (American Sign Language ou ASL), ainda que tenha pesquisado um pequeno número de itens. A autora utilizou uma medida subjetiva para saber quais sinais poderiam ser considerados como de alta ou de baixa frequência. Em seu estudo, por meio de uma escala com ranqueamento de sinais, os participantes surdos nativos da ASL deram notas para expressar se os sinais que lhes era apresentado eram muito ou pouco usados dentro da comunidade surda. Os resultados levaram a criação de dois grupos de sinais sendo um com alta frequência e outro com baixa frequência. Os grupos de sinais foram utilizados em uma Tarefa de Reconhecimento de Sinais. Os resultados indicaram a facilitação do reconhecimento para os sinais com alta frequência.

Por muito tempo, esse tipo de verificação foi utilizada em estudos com ASL. No entanto, como Johnston (2012) argumenta, a verificação feita especificamente para determinados estudos usava pequenos grupos de sinais bem como recuperava informações lexicais a partir da perspectiva de um pequeno grupo de surdos usuários da ASL. Como o autor defende, a observação da frequência de ocorrência de sinais, assim como de palavras, é importante para que os resultados dos estudos possam ser generalizados. O trabalho de Johnston (2012) é considerado um divisor de águas no sentido de lançar a base para a consideração de aspectos lexicais das línguas de sinais dentro de um corpus maior e mais confiável.

Nessa mesma linha, Mayberry, Hal e Zvaigzne (2014) organizaram um estudo com um corpus contendo um léxico inicial de 432 sinais da ASL. Esse estudo obteve uma medida subjetiva quanto à frequência de ocorrência dos sinais com base em uma coleta de dados com 59 surdos nativos da ASL. Além disso, os autores correlacionaram a medida subjetiva, a saber, a declaração dos participantes sobre o quão frequentes na língua os sinais são, com outras medidas, como o grau de conhecimento do sentido dos sinais e a idade em que os indivíduos testados foram expostos à língua de sinais. Essa análise se justifica devido ao grande número de surdos que são expostos à uma língua de sinais tardiamente. Os resultados da investigação estabeleceram uma correlação positiva entre a idade inicial de exposição à língua de sinais, o grau de conhecimento do sinal e a medida subjetiva de frequência de ocorrência. Ao fornecer um banco de dados mais confiável para estudos com a ASL, a pesquisa desenvolvida por Mayberry, Hal e Zvaigzne (2014) enriquece a confiabilidade e amplia as possibilidades de estudos envolvendo a ASL. Visto que a frequência de ocorrência de palavras se vale de técnicas de coleta e análise de corpus por tecnologia de informação de palavras escritas ou orais, e essa tecnologia ainda não é uma realidade para as línguas de sinais, essa variável representou uma dificuldade a ser superada na seleção das palavras para a nossa tarefa ${ }^{1}$.

Além da frequência de ocorrência, a iconicidade é considerada um elemento importante na construção do sinal e por isso precisa ser observada durante a elaboração de tarefas psicolinguísticas envolvendo

\footnotetext{
1 No Brasil, alguns estudos com corpus linguísticos da Libras estão em andamento por meio do projeto Corpus/Libras, disponível em $<$ http://corpuslibras.ufsc.br>. Até o período da construção da Tarefa de Reconhecimento de Tradução, entretanto, não foram encontradas pesquisas compilando corpus linguístico da Libras com medidas de frequência de ocorrência dos sinais.
} 
bilinguismo bimodal. As línguas de sinais apresentam características icônicas particulares. Segundo Taubb (2001), a iconicidade é inicialmente definida como um mapeamento entre a forma como o sinal é articulado e a forma do objeto, ação ou conceito que o sinal reflete. Um exemplo desse tipo de iconicidade pode ser visto no sinal ABELHA, reproduzido abaixo. À primeira vista, o percurso que o sinal transcorre, no espaço na frente do sinalizante, se assemelha ao percurso realizado por uma abelha no mundo natural.
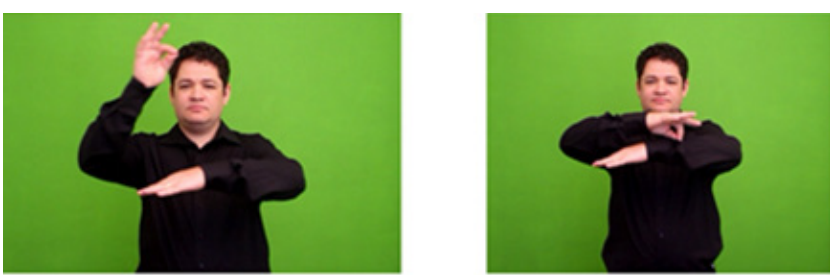

Figura. 1 Sinal: ABELHA

Fonte: elaborado pelos autores.

A semelhança ou mapeamento entre o sinal e o objeto/ conceito ao qual ele se refere se dá, também, entre a forma do sinal e a imagem mental que os falantes tentam retratar por meio da linguagem. Taubb (2001) argumenta que a iconicidade é um esforço mental que as pessoas fazem para relacionar imagens mentais, fazendo uma associação da linguagem com o mundo natural e cultural. Um exemplo do aspecto cultural da iconicidade fica evidente no fato de as línguas de sinais de países diferentes não criarem exatamente o mesmo sinal para objetos considerados icônicos, como o sinal de ÁRVORE, por exemplo. Por fim, é importante ressaltar que existe variabilidade na percepção que os indivíduos possuem do nível de iconicidade dos sinais. Os estudos psicolinguísticos estudam essa característica do sinal a fim de verificar se ela causa algum efeito particular no uso da linguagem, quando a iconicidade é uma variável independente do estudo, ou têm o cuidado de controlá-la, quando o pesquisador utiliza sinais com o mesmo grau de iconicidade (baixo ou alto) em sua lista de itens na tarefa, para que esse aspecto linguístico não afete os resultados do estudo.

Um estudo importante sobre o papel da iconicidade da ASL no acesso lexical é o de Bosworth e Emmorey (2010), que considerou a possibilidade de aumento do efeito de priming semântico, além de um efeito de facilitação do reconhecimento de sinais, quando os itens alvo eram considerados icônicos em comparação aos não icônicos. No experimento realizado, um total de 20 adultos, todos surdos sinalizantes, realizaram uma tarefa de decisão lexical na qual o sinal alvo era precedido por sinais organizados nas seguintes condições: (a) icônico e semanticamente relacionado; (b) não icônico e semanticamente relacionado; e (c) semanticamente não relacionado. Os resultados obtidos sugerem o efeito de priming semântico, apesar de não ter sido encontrado diferença entre o tempo de resposta dos participantes nos itens envolvendo sinais icônicos e não icônicos.

Além disso, o resultado de uma pesquisa com crianças surdas usuárias da Língua Britânica de Sinais (British Sign Language, BSL) (THOMPSON et al., 2012) questionou o possível papel da iconicidade para o aprendizado das línguas de sinais em crianças surdas britânicas. Os participantes eram pais surdos cujos filhos também eram surdos em idade de aquisição da linguagem. Eles registraram em um formulário os sinais que os seus filhos aprenderam e a idade em que eles estavam. Uma análise posterior do grau de iconicidade desses sinais sugeriu uma facilitação de aprendizado do sinal quando este é de natureza mais icônica do que arbitrária, podendo o nível de iconicidade até mesmo predizer estágios de compreensão e de produção do sinal. Os resultados são discutidos no sentido de ressaltar o papel da iconicidade para o processamento da linguagem. No que tange aos aprendizes e usuários ouvintes de uma língua de sinais, um estudo com a ASL questionou em que medida o nível de iconicidade poderia impactar iniciantes e proficientes da ASL (BAUS; CARREIRAS; EMMOREY, 2013). Os participantes realizaram uma Tarefa de Reconhecimento de Tradução e uma Tarefa de Produção de Tradução, traduzindo sinais considerados icônicos e não icônicos. Os resultados mostraram que a iconicidade desempenhou um papel diferenciado somente para os aprendizes, mas não interferiu nas respostas dos participantes proficientes em ASL. Os autores discutem esses resultados como possivelmente caracterizando a iconicidade como uma ferramenta quando o contexto exigir o aprendizado do sinal ou durante o processo de introdução de um novo conceito em contextos de aprendizagem de uma língua de sinais.

\section{Co-ativação das línguas}

Outro aspecto relevante no que tange a construção de uma tarefa psicolinguística diz respeito à forma como as línguas parecem estar organizadas na mente do bilíngue. Isso acontece porque, como estudos indicam, os bilíngues ativam os equivalentes da segunda língua que conhecem mesmo em contextos de interação em que que estejam usando somente sua primeira língua (TOKOWICZ; 2015).

Isso pôde também ser observado no estudo de Emmorey, Borinstein, Thompson e Gollan e colegas (2008), que analisou em que medida a especificidade da modalidade linguística da ASL - uma língua de sinais - 
poderia causar um efeito na forma como os bilíngues recorrem à informação nessa língua enquanto interagem utilizando uma língua oral. Os 11 participantes eram filhos de surdos e adquiriram ASL na infância. Eles foram solicitados a assistir um vídeo de um desenho animado com uma narrativa sem diálogos e depois contá-la em inglês ou em ASL para um colega que também estava participando da pesquisa. Foi constatado que eles utilizavam muito o que os pesquisadores chamam de code-blending. Esse fenômeno se caracterizou pelo uso concomitante da fala e do sinal em determinadas partes do discurso. Embora uma das línguas tenha se mantido como a língua matriz, como por exemplo o inglês, em muitos momentos os sinalizantes utilizavam também um sinal ao mesmo tempo. Nos resultados, os autores sugerem que os sinais utilizados foram usados para complementar o sentido com uma informação que estava mais clara na língua de sinais do que na língua oral. Esse resultado chama a atenção para a possibilidade de que as duas línguas dos bilíngues bimodais também ficam ativas e são utilizadas enquanto eles interagem.

Emmorey; Petrich e Gollan (2012) investigaram, por meio de dois experimentos subsequentes, o processamento linguístico em bilíngues proficientes em ASL e em inglês, em condições onde o code-blending pode ser uma indicação de co-ativação das duas línguas de modalidades distintas. O objetivo desses experimentos foi verificar em que medida línguas de modalidades diferentes como a ASL e o inglês poderiam ser acessadas ao mesmo tempo e como isso poderia afetar o reconhecimento e a produção de palavras e de sinais. Um total de 47 ouvintes bilíngues ASL-inglês, divididos em dois grupos - indivíduos que aprenderam ASL quando crianças e indivíduos que a aprenderam quando adultos, participaram do estudo. Os participantes foram solicitados a nomear 120 figuras apresentadas em um computador, sendo que 40 figuras foram nomeadas em inglês, 40 em ASL e 40 em code-blending. Os resultados sugerem que a nomeação de figuras utilizando o code-blending não implicou na necessidade de mais tempo para a recuperação lexical para os sinais da ASL. No entanto, o code-blending atrasou a produção da fala, visto que os participantes sincronizavam o começo da fala do inglês e do sinal da ASL. Os mesmos autores produziram um segundo experimento para verificar se haveria algum impacto do code-blending na forma como os bilíngues percebem os sinais. Nesse experimento, 45 participantes reagiram a uma tarefa de categorização semântica que continha 90 itens lexicais. Nela, eles viam um sinal, ouviam uma palavra ou um code-blending e respondiam se o que estava sendo dito se referia a algo comestível. O resultado dessa tarefa de compreensão indicou que as respostas dos participantes na condição code-blending foi mais rápida do que nas condições de itens em inglês ou em ASL isoladamente, o que sugere que essa condição acelera o acesso às duas línguas. A partir desses resultados, os autores argumentam que pode existir, no bilinguismo bimodal, um mecanismo interlinguístico bimodal de integração no nível fonológico ou no nível semântico que pode influenciar o processamento da linguagem.

Shook e Marian (2012) olharam de forma experimental para o comportamento de duas línguas de modalidades diferentes, ASL e inglês, enquanto somente uma era evocada. A tarefa, chamada de World Paradigm, consiste em uma sequência de telas no computador com quatro imagens. O nome de uma das imagens aparece acima delas e os participantes são solicitados a clicar na imagem correspondente. No experimento, todas as instruções foram dadas em inglês e os participantes foram divididos em dois grupos, sendo um composto por bilíngues ASL-inglês e outro por monolíngues falantes de inglês. A tarefa continha itens alvo, por exemplo, queijo, um item competidor, por exemplo, papel e dois itens distratores, todos visualizados como imagens, sendo que as palavras "queijo" e "papel" em ASL usam a mesma configuração de mão, locação e orientação, mas diferem quanto ao movimento. Para verificação da resposta dos participantes, foi utilizado um eye-tracker. A análise do movimento dos olhos indicou que os participantes fixaram o olhar de forma significativa para o item competidor do que para os distratores, resultado que sugere a ativação das duas línguas em paralelo, mesmo que uma delas não tenha sido usada durante a tarefa.

Por fim, é interessante destacar que essa ativação das duas línguas do bilíngue bimodal também pode ocorrer por meio da relação fonológica da tradução das palavras e dos sinais. Isso foi observado em um estudo sobre ativação linguística dupla e a seleção lexical em bilíngues bimodais (GIEZEN; EMMOREY, 2016), no qual os participantes foram solicitados a nomear imagens em ASL enquanto ouviam palavras em inglês. Essas palavras foram manipuladas de forma a estarem divididas em quatro condições: (a) equivalentes de tradução; (b) palavra relacionada fonologicamente com o sinal alvo por meio da tradução (c) palavra relacionada semanticamente; ou (d) palavra não relacionada. Os resultados indicaram que houve uma facilitação de produção do sinal (aceleração da resposta) quando os participantes ouviam uma palavra em inglês que, embora não fosse condizente com a imagem que deveriam nomear através do sinal, compartilhava parâmetros fonológicos como configuração de mão, locação e movimento com a imagem alvo. Os autores discutem esse resultado como uma evidência para a ativação interlinguística a partir do nível fonológico do sinal. 
A possibilidade de haver ativação paralela das línguas no bilinguismo bimodal foi considerada na composição da Tarefa de Reconhecimento de Tradução LibrasPortuguês que será descrita abaixo, pois considerou-se que, ao visualizarem um sinal da Libras, mesmo que a resposta devesse ser dada em Português, os participantes iriam ativar o conhecimento dos aspectos fonológicos da Libras analisados acima, a saber, configuração de mão, locação e movimento de um sinal, a orientação da mão e o caminho do movimento, além de ativar aspectos não manuais, como a expressão facial gramatical. Portanto, se os itens da tarefa (prime em Libras e alvo em Português) compartilhassem algum aspecto fonológico, essa interferência poderia influenciar os resultados. Por essa razão, foi feito controle rigoroso desse aspecto na seleção dos itens da tarefa.

\section{Tamanho das palavras e o tempo dos vídeos dos sinais}

Além dos aspectos já mencionados, outras variáveis precisam ser controladas numa tarefa psicolinguística, como o tamanho das palavras, que afeta diretamente o tempo do reconhecimento dos itens alvo, tanto em tarefas de compreensão como de produção de palavras. O cuidado metodológico em pesquisas que investigam o bilinguismo bimodal também envolve o tamanho da produção do estímulo apresentado para os participantes. As pesquisas com línguas orais usam, em grande escala, estímulos na modalidade escrita. No caso das línguas de sinais, o ensino e uso geral da língua escrita não é tão comum como no caso das línguas orais e por isso tornou-se uma prática para os pesquisadores apresentar os estímulos por meio de pequenos vídeos gravados com um sinalizante nativo. O controle do tamanho do vídeo envolve o tamanho dos vídeos, garantindo que eles sejam apresentados com o mesmo tempo de duração (MORFORD, NICODEMUS, WILKINSON, 2015)

Em suma, este primeiro segmento deste artigo teve como objetivo discutir critérios importantes a serem considerados na confecção de um instrumento de pesquisa psicolinguístico envolvendo línguas de sinais. Foram apresentadas informações sobre o método quase experimental em estudos de causa e efeito que utiliza o registro do tempo de reação dos participantes. Também foi destacado o papel de algumas características lexicais cujo impacto na produção ou no reconhecimento lexical já são conhecidos. A seguir, este artigo descreve o processo de criação de uma Tarefa de Reconhecimento de Tradução em Libras - Português que foi aplicada em um grupo de bilíngues ouvintes que atuavam como tradutores e intérpretes de Libras e reflete sobre o seu processo de criação a partir dos aspectos metodológicos considerados em um estudo sobre o acesso lexical no bilinguismo bimodal.

\section{Tarefa de Reconhecimento de Tradução Libras-Português}

O objetivo desta seção é exemplificar as questões de ordem linguística e metodológica acima explicitadas por meio da descrição das etapas de confecção de uma Tarefa de Reconhecimento de Tradução utilizando o par linguístico Libras - Português. Essa tarefa foi construída como parte da pesquisa que deu origem à dissertação de mestrado intitulada Bilinguismo bimodal: um estudo sobre o acesso lexical em intérpretes de Libras - Português (FONSECA, 2015).

\section{Decisões metodológicas}

O primeiro passo para a criação de uma tarefa psicolinguística envolve a tomada de decisões metodológicas para determinar o objeto de estudo e consequentemente a melhor forma de compor o instrumento de pesquisa. No presente estudo, a motivação girou em torno do aprofundamento do conhecimento sobre a organização das línguas na mente do bilíngue no contexto do bilinguismo bimodal. Teoricamente, a pergunta que deu base para o estudo foi em que medida línguas de modalidade distintas, como a Libras e o Português, são organizadas de forma separada ou em conjunto na mente dos bilíngues. Nesse contexto teórico, a pesquisa relatada na dissertação teve como objetivo geral analisar de que forma a modalidade visuoespacial da Libras e a experiência dos bilíngues enquanto tradutores e intérpretes de Libras poderiam impactar na organização dos sinais e das palavras.

O objetivo específico do trabalho, que foi verificado através da Tarefa de Reconhecimento de Tradução relatada neste artigo, foi o de investigar o efeito de interferência semântica no acesso lexical bilíngue bimodal em um grupo de adultos ouvintes bilíngues bimodais que atuam como tradutores e intérpretes de Libras-Português ${ }^{2}$. O efeito de interferência semântica foi obtido por meio da comparação das três condições do estudo, abaixo discriminadas, e medido através da diferença no tempo de reação de cada condição. As variáveis dependentes do estudo foram o tempo de reação e o percentual de erros produzidos pelos participantes na realização da Tarefa de Reconhecimento de Tradução. A variável independente intra-sujeito diretamente relacionada com

\footnotetext{
2 Na pesquisa, também fez-se uso de um Questionário de Histórico de Linguagem (FLORES; FINGER, 2014) para avaliar outras variáveis investigadas no estudo que, por razões de escopo, não será apresentado neste artigo.
} 
o instrumento utilizado foi a interferência semântica apresentada nos pares de sinal/palavra nas seguintes condições de tradução: tradução correta, tradução incorreta relacionada semanticamente e tradução incorreta não relacionada semanticamente. A manipulação da variável independente gerou as seguintes condições experimentais:

A. Tradução correta: nesse caso, a palavra-alvo em Português não somente está dentro do campo semântico do sinal como também é utilizada como a sua tradução em Português. Por exemplo: ÁGUA (em Libras) e Água (em Português).

B. Tradução incorreta semanticamente relacionada: acontece quando existe uma relação de proximidade semântica entre o sinal em Libras (prime) e a palavra-alvo em Português, mas a palavra não corresponde à tradução correta do sinal, pois existe outra tradução consagrada. Por exemplo: LÁPIS (em Libras) e Borracha (em Português).

C. Tradução incorreta semanticamente não relacionada: nesse caso, a palavra-alvo em Português, que não é a tradução correta do sinal, também não apresenta relação semântica com o sinal (prime). Exemplo: AREIA (em Libras) e Dragão (em Português).

\section{Organização dos estímulos linguísticos}

Após a tomada de decisão quanto aos aspectos metodológicos a serem seguidos, o próximo passo foi a organização dos sinais e palavras que seriam usados como estímulos dentro da Tarefa de Reconhecimento de Tradução. Essa tarefa consiste em o participante visualizar um sinal, seguido de uma palavra e dizer se aquela palavra corresponde à sua tradução. Para compor a tarefa foi necessário criar uma lista de sinais em Libras e palavras subsequentes em Português nas três condições do estudo: tradução correta, tradução incorreta semanticamente relacionada; e tradução incorreta semanticamente não relacionada.

A organização do conjunto dos itens lexicais da Libras e do Português que seriam usados como primes e alvo na Tarefa de Reconhecimento de Tradução partiu inicialmente de uma lista de sinais da Libras coletada em documentos que registram a língua de sinais, como dicionários e apostilas e elaboradas em cursos de Libras. Além disso, uma consulta a intérpretes de Libras e professores surdos também foi realizada no sentido de assegurar a usabilidade daqueles sinais. Esse primeiro passo gerou a exclusão de alguns itens não usuais.

Para atingir o objetivo do estudo, foi necessário encontrar os pares de palavras associadas semanticamente.
Um associado semântico se constitui numa palavra próxima a outra na organização do léxico mental. Assim, por exemplo, durante a tarefa o vídeo do sinal CENOURA poderia ser apresentado e seguido da palavra "coelho", que por sua vez deveria ser considerado pelo participante como uma tradução errada. Porém, esse par de itens poderia causar um efeito de interferência por causa da associação semântica das palavras "cenoura" e "coelho", fazendo com que o tempo de reação fosse maior do que o vídeo do sinal CENOURA seguido da palavra "escola", por exemplo. Isso aconteceria por "escola" não ser um associado semântico de "cenoura", mas poderia ser de "estudar". Para usar listas de sinais juntamente com as suas traduções em Português bem como as palavras que são e que não são associadas semanticamente a essas traduções, verificou-se primeiramente trabalhos na literatura sobre associação semântica em Português. O trabalho de Salles (2008), com 88 itens associados, supriu alguns dos itens necessários. A autora distribuiu aos participantes do seu estudo uma lista de palavras e solicitou que informassem a primeira palavra que lhes viesse à mente. Nem todos os itens dessa lista foram utilizados porque somente alguns eram iguais à lista de sinais da Libras e traduções previamente organizada. Assim, para preencher os itens faltantes, foi necessário fazer um breve estudo sobre associação semântica.

Assim como no trabalho de Salles (2008), foi criada uma lista de palavras em Português que correspondiam às traduções dos sinais da Libras selecionados anteriormente. O próximo passo foi apresentar esta lista com 70 palavras para 140 estudantes universitários de quatro cursos de graduação diferentes, Pedagogia, Medicina, Administração e Ciências Contábeis, nas cidades de Canoas, Osório e Porto Alegre. Cada participante recebeu um formulário com a lista e foi solicitado a escrever ao lado de cada item a primeira palavra que lhes viesse à mente. Após a coleta de dados, foi feita a contagem dos itens mais recorrentes e a retirada daqueles que tivessem similaridade fonológica com a palavra alvo, visto que o objetivo era ter uma lista de itens apenas relacionados semanticamente.

As palavras mais recorrentes forneceram a confirmação da relação semântica necessária para o estudo e para a criação da Tarefa de Reconhecimento de Tradução Libras - Português. Assim, foram gerados os pares com o sinal em Libras (prime) e palavra (alvo) em Português.

Outro aspecto controlado durante a construção da tarefa foi a frequência de ocorrência das palavras em Português. Como vimos, esta é uma variável importante que pode atuar como facilitador ou dificultador do acesso lexical e processamento da linguagem. Em termos práticos, na Tarefa de Reconhecimento de Tradução, os 
participantes não poderiam ver um sinal cuja tradução em Português fosse uma palavra de alta frequência seguido por uma palavra de baixa frequência. Essa variável impactaria o tempo de reação pois palavras mais frequentes são acessadas mais rapidamente do que palavras menos frequentes. Essa medida foi obtida a partir dos dados do banco de dados SUBTLEX-PT-BR ${ }^{3}$. No caso de estudos que abrangem o reconhecimento de palavras como traduções, o resultado não deve também ser influenciado pelo tamanho maior ou menor de palavras (de GROOT, 1992). Por isso, os itens em Português, ou seja, as palavras-alvo, foram controladas de forma a excluir os sinais cujas traduções apresentavam um número de letras muito distante da média. Quanto à frequência de ocorrência de sinais, como não foi encontrado no Brasil um banco de dados com informações lexicais que incluam a frequência de ocorrência de sinais da Libras, optou-se por usar como fonte de sinais em materiais didáticos com listas comumente conhecidas, como apostilas de cursos, bem como consultar intérpretes e professores surdos, ainda que informalmente, quanto a se os sinais eram de uso comum ou não dentro da comunidade surda.

Também é importante lembrar que o foco do estudo foram as relações semânticas em Português. Ou seja, o estudo teve como foco verificar se a relação semântica das palavras em Português causaria um efeito de interferência medida por um tempo maior ao responder a tarefa. Isso também implica dizer que o acesso lexical por meio da Libras poderia não somente acionar a sua tradução em Português, mas também os itens relacionados a ela. Portanto, outro aspecto controlado em relação aos itens que compuseram a tarefa diz respeito à questão da dupla ativação das línguas a partir da tradução. Nesse sentido, foi realizada a exclusão de primes cujos aspectos fonológicos, como a configuração de mão, locação e movimento, pudessem acelerar a resposta de traduções não relacionadas semanticamente ou ainda de traduções erradas, devido à semelhança fonológica entre o prime e a tradução. Assim, por exemplo, o sinal prime CENOURA compartilha a configuração de mão na condição não relacionada com a palavra-alvo indicada como tradução "Bicicleta". Para isso, foi conduzida uma análise fonética e fonológica dos parâmetros linguísticos de todos sinais, que foram comparados com os parâmetros de todos os equivalentes em tradução para Libras. Foram excluídos os casos onde havia compartilhamento de mais de um parâmetro, como foi o caso de CENOURA e "Bicicleta".

Dentre os aspectos não manuais da Libras, foi monitorado o uso do lábio. Alguns autores dividem o uso do lábio na sinalização como mouth gestures ou como mouthing (FERREIRA, 2010a; QUADROS;

\footnotetext{
3 Encontrado no site www.crr.ugent.be
}

KARNOPP, 2004a; SANDLER; LILLO-MARTIN, 2006). O primeiro representa uma configuração labial com valor morfológico associado a algum sentido na Libras, ao passo que o segundo corresponde à articulação total de uma palavra da língua oral enquanto se produz um sinal. Na construção da tarefa, um professor surdo nativo na Libras foi convidado a participar na sinalização do estímulo e ganhou a liberdade para fazê-los na forma como pensasse que os surdos fazem na sua vida diária. Isso significou aceitar a presença de expressões labiais.

\section{A confecção da tarefa}

Foram criadas no Excel três listas de estímulos do tipo sinais (prime) e palavras (itens alvo), de forma que o mesmo sinal pudesse ser visto seguido por palavras nas três condições do estudo. Em uma das listas, um determinado sinal (prime) aparece ao lado da palavra (alvo) na sua tradução correta; em outra lista, ele aparece ao lado da tradução incorreta semanticamente relacionada e, por fim, em uma terceira lista, o mesmo sinal aparece seguido de uma tradução incorreta semanticamente não relacionada. Cada participante realizou apenas uma versão da tarefa, que continha itens das três listas

Em cada lista de estímulos, foram elaborados 78 pares de sinais (prime) em Libras e palavras-alvo em Português, sendo 19 pares de sinal em Libras e tradução correta em Português, 20 pares de sinal em Libras e tradução incorreta semanticamente relacionada em Português, 19 pares de sinal em Libras e tradução incorreta e semanticamente não relacionadas em Português e 19 pares de fillers, ou seja, pares que não seguem o critério de criação das condições de estudo, que foram inseridos entre os estímulos para dificultar a identificação do objetivo da pesquisa pelo participante durante a execução da tarefa.

Com as listas prontas, o passo seguinte consistiu na produção dos estímulos da Libras para serem adicionados ao E-prime como vídeo. A filmagem foi feita por um professor surdo nativo na Libras para garantir que não houvesse interferência ou estranhamento causado pela possível presença de sotaque de uma pessoa ouvinte. O local da filmagem foi um pequeno estúdio no apartamento desse professor, com equipamento Canon EOS 60D posicionado contra um fundo verde. A preparação do espaço e filmagem exigiu dois turnos. Na fase de edição, cada estímulo em Libras ficou com o mesmo tempo de apresentação de vídeo: um segundo e quarenta milissegundos.

Depois da gravação dos vídeos com os estímulos prime, foi realizada a composição final da tarefa. Primeiramente os vídeos foram editados, e em seguida foram compilados na Tarefa de Reconhecimento de Tradução no E-prime 2.10 (2010). Essa etapa consistiu no upload dos estímulos, onde os vídeos em Libras 
e as palavras propostas para serem apresentadas individualmente após cada vídeo foram pareados, de acordo com as três condições semânticas do estudo. O software foi programado para apresentar cada vídeo em Libras, previamente editado para ter um segundo e quarenta milissegundos e, em seguida, a tela com a palavra alvo em Português por dois segundos. Além disso, foi providenciada a randomização da ordem de apresentação dos estímulos, para evitar que a mesma ordem de apresentação dos estímulos pudesse ter um impacto no resultado final. Outro aspecto importante da composição da tarefa foi a criação de telas iniciais com instruções claras e padronizadas para todos os participantes, pois é importante que os sujeitos tenham compreensão clara dos procedimentos de execução da tarefa. A fim de garantir isso, na primeira fase da tarefa foi organizada ainda uma sessão de prática, na qual os participantes puderam treinar os procedimentos a serem adotados. Após cinco sequências de vídeos seguidos de traduções, foi incluída uma tela sinalizando o início da tarefa.

\section{O teste piloto e a aplicação da tarefa}

O estudo piloto envolveu a aplicação da tarefa com dois intérpretes de Libras. Durante essa fase, foram feitos ajustes em pequenos erros encontrados, bem como foi obtida uma noção do tempo total de realização da tarefa e uma antecipação de como os participantes da pesquisa poderiam se sentir.

A tarefa foi apresentada aos participantes em um notebook Dell, em uma sala reservada da universidade ou local silencioso previamente planejado. O primeiro passo da aplicação da tarefa foi organizar uma tabela de registro de participantes, que possibilitou a divisão randômica da versão da tarefa que seria aplicada a cada participante, ou seja, Versão A, B, ou C. Após a assinatura do Termo de Consentimento Livre e Esclarecido, a coleta de dados foi conduzida da seguinte forma.

Num primeiro momento, aparece uma tela solicitando o número do candidato e, em seguida, o número da seção de trabalho, informação preenchida pelo aplicador da pesquisa. A seguir, o participante visualiza a tela com instruções para a realização da tarefa. Nela, o participante recebe primeiramente a orientação para dizer se a palavra corresponde à tradução do sinal que a antecede pressionando a tecla $\mathrm{S}$ para sim e $\mathrm{N}$ para não. A seguir, o participante é solicitado a pressionar a tecla espaço para ir para o próximo vídeo. No caso de o participante é informado de que, se não tomar nenhuma decisão no tempo estabelecido, o experimento automaticamente o conduzirá para o próximo vídeo. Cada par de sinal e palavra aparece intercalado pelo sinal + , que avisa que o próximo vídeo está pronto.

A tela de instrução informa ao participante que ele deve se posicionar com as mãos próximas ao teclado, que deve responder o mais rapidamente possível e que o celular deve estar desligado. Por fim, é dada ao participante a possibilidade de fazer algum questionamento e, antes de a testagem iniciar, há uma breve seção de prática para que o participante possa se familiarizar com o experimento. A estrutura da Tarefa de Reconhecimento de Tradução aparece na Figura 2 abaixo.

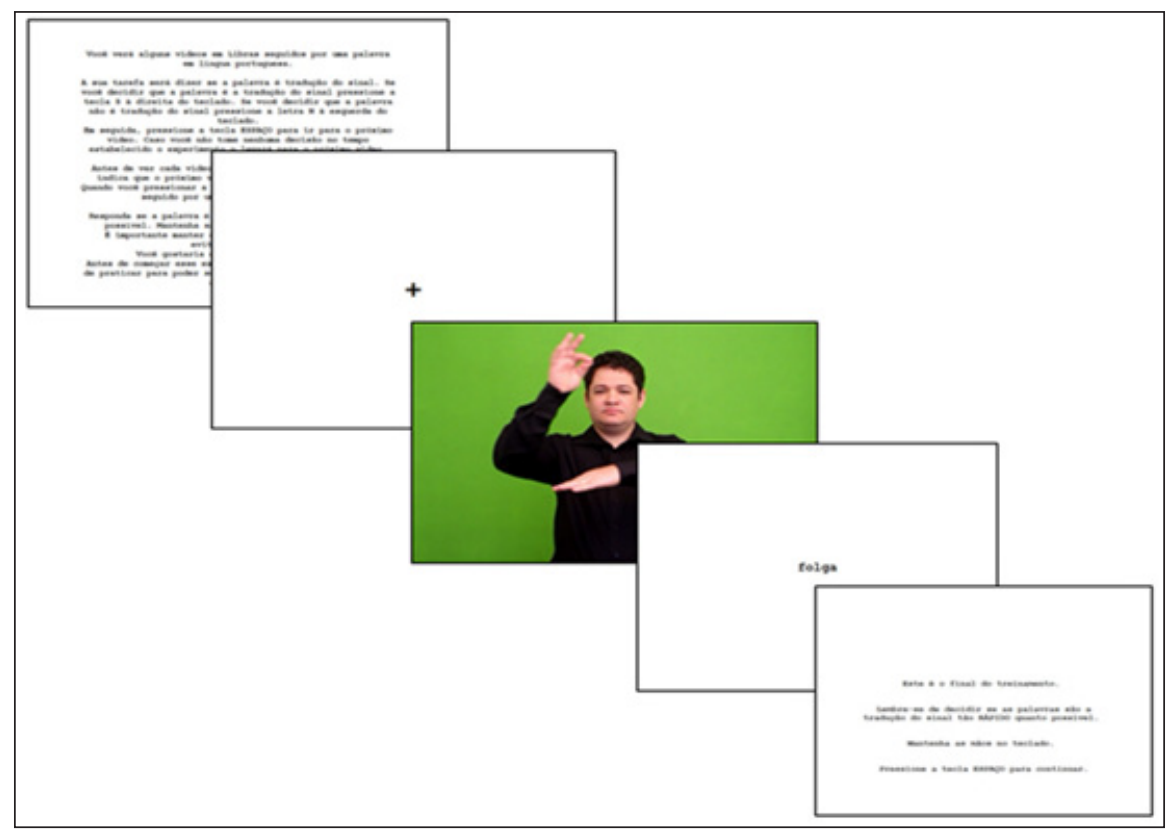

Figura 2. Sequência de telas na Tarefa de Reconhecimento de Tradução Fonte: Elaborado pelos autores. 
Finalmente, enfatiza-se que esta Tarefa de Reconhecimento de Tradução atende critérios rigorosos no estudo da realidade psicolinguística no bilinguismo bimodal. Ela foi de fato implementada e se mostrou efetiva para os propósitos da pesquisa. A sua confecção representada um passo no caminho da compreensão do léxico mental da Libras, em termos de sua organização e de seu processamento.

\section{Considerações finais}

Este artigo teve como objetivo discutir os aspectos metodológicos da pesquisa psicolinguística por meio de instrumentos que registram o tempo de reação no contexto do acesso lexical bilíngue bimodal através da apresentação das etapas de construção de uma Tarefa de Reconhecimento da Tradução em Libras e Português Brasileiro. Os estudos dessa natureza ainda são recentes no mundo e mais ainda no Brasil. Espera-se que este artigo possa motivar a criação de outros experimentos por meio de tarefas e metodologia semelhantes para que se possa desenvolver um corpo de conhecimento psicolinguístico em torno da Libras e sua relação com o Português.

\section{Referências}

BAUS, C.; CARREIRAS, M.; EMMOREY, K. When does iconicity in sign language matter? Language and Cognitive Processes, v. 28, n. 3, p. 261-271, abr. 2013.

BOSWORTH, R. G.; EMMOREY, K. Effects of iconicity and semantic relatedness on lexical access in American sign language. Journal of Experimental Psychology: Learning, Memory, and Cognition, v. 36, n. 6, p. 1573-1581, 2010.

CASELLI, N. K. et al. ASL-LEX: A lexical database of American Sign Language. Behavior Research Methods, v. 49, n. 2, p. 784-801, abr. 2017.

CHRISTENSEN, L. B.; JOHNSON, B.; TURNER, L. A. Research methods, design, and analysis. 12. ed. Boston: Pearson, 2014.

EMMOREY, K. (1990) [Sign frequency effects on reaction time in an ASL lexical decision task] Unpublished raw data.

EMMOREY, K. Language, cognition, and the brain: insights from sign language research. Mahwah, N.J: Lawrence Erlbaum Associates, 2002.

EMMOREY, $\mathrm{K}$ et al. Bimodal bilingualism. Bilingualism: Language and Cognition, v. 11, n. 1, mar. 2008. Disponível em: <http://www.journals.cambridge.org/abstract_ S1366728907003203>. Acesso em: 1o maio 2017.

EMMOREY, K. Iconicity as structure mapping. Philosophical Transactions of the Royal Society B: Biological Sciences, v. 369, n. 1651, p. 20130301-20130301, ago. 2014.

EMMOREY, K.; PETRICH, J. A. F.; GOLLAN, T. H. Bilingual processing of ASL - English code-blends: The consequences of accessing two lexical representations simultaneously. Journal of Memory and Language, v. 67, n. 1, p. 199-210, 2012.
FERREIRA, L. Por uma gramática de línguas de sinais. 2. ed. rev. pela nova gramática da língua portuguesa por Junia Camarinha ed. Rio de Janeiro: Tempo Brasileiro, 2010a.

FLORES, V. M.; FINGER, I. Proposta de questionário de histórico de linguagem e autoavaliação de proficiência para professores ouvintes bilíngues libras/língua portuguesa. Signum: Estudos da Linguagem, v. 17, n. 2, p. 278, 2014.

FONSECA, SANDRO. Bilinguismo bimodal : um estudo sobre o acesso lexical em intérpretes de libras-Português. Porto Alegre, RS: Universidade Federal do Rio Grande do Sul, 2015. Disponível em: <http://www.lume.ufrgs.br/ handle/10183/132680?show=full>. Acesso em: 25 out. 2017.

GIEZEN, M. R.; EMMOREY, K. Language co-activation and lexical selection in bimodal bilinguals: Evidence from pictureword interference. Bilingualism: Language and Cognition, v. 19, n. 2, p. 264-276, 2016.

GROOT, A. M. de. Determinants of word translation. Journal of Experimental Psychology: Learning, Memory, and Cognition, v. 18, n. 5, p. 1001, 1992.

JIANG, N. Conducting reaction time research in second language studies. New York: Routledge, 2012.

JOHNSTON, T. Lexical Frequency in Sign Languages. Journal of Deaf Studies and Deaf Education, v. 17, n. 2, p. 163-193, 2012.

JOHNSTON, T. A.; SCHEMBRI, A. Australian sign language (Auslan): an introduction to sign language linguistics. Cambridge, UK; New York: Cambridge University Press, 2007. OCLC: ocm 71347519 .

MARIAN, V.; BLUMENFELD, H. K.; KAUSHANSKAYA, M. The Language Experience and Proficiency Questionnaire (LEAP-Q): Assessing language profiles in bilinguals and multilinguals. Journal of Speech, Language, and Hearing Research, v. 50, n. 4, p. 940-967, 2007.

MAYBERRY, R. I.; HALL, M. L.; ZVAIGZNE, M. Subjective frequency ratings for 432 ASL signs. Behavior Research Methods, v. 46, n. 2, p. 526-539, 2014.

MORFORD, J. P.; MACFARLANE, J. Frequency Characteristics of American Sign Language. Sign Language Studies, v. 3, n. 2, p. 213-225, 2003.

MORFORD, J.P. NICODEMUS, B., WILKINSON, E. Research methods in pshycholinguistcs investigations of sign language processing. In: ORFANIDOU, E.; WOLL, B.; MORGAN, G. (Org.). Research methods in sign language studies. 2015.

ORTEGA, G. Iconicity and Sign Lexical Acquisition: A Review. Frontiers in Psychology, v. 8, ago. 2017. Disponível em: <http:// journal.frontiersin.org/article/10.3389/fpsyg.2017.01280/full>. Acesso em: 25 out. 2017.

PERNISS, P.; THOMPSON, R. L.; VIGLIOCCO, G. Iconicity as a General Property of Language: Evidence from Spoken and Signed Languages. Frontiers in Psychology, v. 1, 2010. Disponível em: <http://journal.frontiersin.org/article/10.3389/ fpsyg.2010.00227/abstract>. Acesso em: 25 out. 2017.

QUADROS, R. M. de; KARNOPP, L. B. Língua de sinais brasileira: estudos lingüísticos. Porto Alegre: Artmed, 2004a.

SANDLER, W. LILLO-MARTIN, D. Sign language and linguistics universals. 2006. 
SALLES, J. F. de et al. Normas de associação semântica para 88 palavras do Português brasileiro. Psico, v. 39, n. 3, 2008. Disponível em: <http://revistaseletronicas.pucrs.br/ojs/index.php/ revistapsico/article/view/3836/0>. Acesso em: 28 abr. 2017.

SHADISH, W. R.; COOK, T. D.; CAMPBELL, D. T. Experimental and quasi-experimental designs for generalized causal inference. Boston: Houghton Mifflin, 2001.

SHOOK, A.; MARIAN, V. Language Processing across Modalities: Insights from Bimodal Bilingualism. Cognitive Sciences, v. 5, p. 57-98, 2010..

SHOOK, A.; MARIAN, V. Bimodal bilinguals co-activate both languages during spoken comprehension. Cognition, v. 124, n. 3, p. 314-324, set. 2012.

TAUBB, S. F. Language from the body: Iconicity and metaphor in American sign language, 2001.

TAYLOR, S. J.; BOGDAN, R.; DEVAULT, M. Introduction to qualitative research methods: A guidebook and resource. [S.1.]: John Wiley \& Sons, 2015a.
THOMPSON, R. L. et al. The Road to Language Learning Is Iconic: Evidence From British Sign Language. Psychological Science, dez. 2012. v. 23, n. 12, p. 1443-1448.

TOKOWICZ, N. Lexical processing and second language acquisition. New York; London: Routledge, 2015.

VINSON, D. P. et al. The British Sign Language (BSL) norms for age of acquisition, familiarity, and iconicity. Behavior Research Methods, v. 40, n. 4, p. 1079-1087, nov. 2008..

WILLEMS, K.; DE CUYPERE, L. (Org.). Naturalness and iconicity in language. Amsterdam: Philadelphia: John Benjamins Pub. Co, 2008.

Recebido: 30/09/2017

Aprovado: 16/01/2018

Contato:

Sandro Rodrigues da Fonseca <sandrofnsc@gmail.com> 